\title{
Spinal curvatures of children and adolescents - a cross-sectional study
}

\author{
Małgorzata Grabara, Anna Bieniec, Agnieszka Nawrocka \\ Department of Tourism and Health-related Physical Activity, Faculty of Physical Education, Jerzy Kukuczka Academy \\ of Physical Education, Katowice, Poland
}

\section{Summary}

Study aim: The aim was to assess the spinal curvatures of primary and lower secondary male and female students from Silesia and to identify individual variations that can determine spinal posture.

Material and methods: The study involved 331 girls and 286 boys aged 8 to 16 years. Eligible criteria were non-participation in any professional sport training, and participation in mandatory physical education classes. Posture was evaluated using the moiré method. Measurements of somatic parameters were made with a medical scale using a height meter and a Tanita electronic balance.

Results: Dimorphic postural differences of boys and girls were seen mainly in the shape of lumbar lordosis. Girls were more lordotic than boys at all ages except 10-years-olds. Angle $\gamma$ was significantly greater in 9-, 15- and 16-year-old girls than boys. LLA was significantly more prominent in 15- and 16-year-old girls than boys. Thoracic kyphosis was significantly more prominent in 8- and 11-year-old boys than girls. We also found a significant effect of age and somatic parameters. In boys mean lumbar lordosis was more pronounced in 10-year-olds. In girls fat mass, fat percentage and BMI correlated with angle $\alpha$ and angle $\Delta$. In boys body height and mass, fat mass, total body water and BMI correlated with angles $\beta, \gamma, \Delta$, and lordosis lumbar angle.

Conclusions: The shape of lumbar lordosis is associated with age and gender. Lumbar lordosis decreases with age in male children and adolescents. Our study revealed poor correlations between sagittal spinal curvatures and somatic parameters.

\section{Key words: Anteroposterior spinal curvatures - Spine - Somatic parameters - Moiré method}

\section{Introduction}

Posture of the human body depends on a variety of factors, including the physical and mental condition, heredity, age, gender, environmental factors, kinaesthetic sense, muscle balance and neuromuscular coordination $[2,6,10$, 11, 14, 18, 21]. Posture development is also associated with body height and mass, school furniture, physical activity, and generation $[4,13,18]$.

Posture could be defined as the habitual alignment of body parts in an upright stance. Human posture is an indicator of the kinaesthetic sense, muscle balance, and neuromuscular coordination [5]. Proper posture is characterized by symmetry in the frontal and transverse planes. In the sagittal plane the spine has four physiological curves, i.e. lordosis in the cervical and lumbar regions, and kyphosis in the thoracic and sacral regions. The anteroposterior spinal curves are formed at successive stages of ontogenesis. Determination of standards for posture in the sagittal plane is a significant difficulty and largely depends on the measurement technique used.

Posture is constantly changing. At the age when education begins, spinal curvatures are labile as a result of rapid growth. At the age of 6-7 years, thoracic kyphosis is dominant; it is associated with poor muscle tone stabilizing the spine. First the cervical lordosis stabilizes, while an increase in strength of back muscles, at the age of about 8-11 years, increases lumbar lordosis. The posture may become worse from 6 to 10 years old because of changing lifestyle connected with the school education [7]. Adolescence predisposes one to deteriorating posture, which is marked by carelessness and slenderness. Previous studies showed that anteroposterior spinal curvatures change as the child grows $[1,9,12]$. The postural evolution during childhood is characterized by an increase in forward translation displacements of the head, shoulders, pelvis and knees in the sagittal plane [9]. The pre-adolescent phase and adolescence are periods of life with rapid changes in height and weight, and as a result of adaption to new proportions, 
posture also changes. There are a small number of studies analyzing posture in relation to somatic parameters. Periods of rapid growth are sometimes referred to as "critical periods of posturogenesis" [17]. Posture diagnosis during these periods of life is particularly important $[14,15]$; however, studies including children and adolescents in a wide age range have seldom been conducted.

The aim of this study was to assess the posture in terms of sagittal spinal curvatures of randomly selected pupils of primary and lower secondary schools from the Silesia region (southern Poland), and to identify individual variations (e.g. age, gender, body height and mass) that can determine spinal posture.

\section{Material and methods}

\section{Participants}

The study group comprised 617 students of randomly selected schools from the cities of Upper Silesia, Poland. There were 331 girls and 286 boys ages 8-16. All the examined students and their parents/guardians were informed of the procedures and voluntarily signed consent prior to measurements.

Inclusion criteria were: parental permission to participate in the study, non-participation in any professional sport training, and participation in mandatory physical education classes. Participants were excluded from the study in case of an incomplete application, pathology of the motor organs, injuries, lack of written parental consent, and if they regular participated in any professional sport training.

\section{Procedures}

The study was approved by the Bioethics Committee of the Academy of Physical Education in Katowice, Poland. Parents of the examined students filled in an informed consent form and a questionnaire to provide information on their child's posture defects, existing pathologies, chronic diseases, any contraindications to physical exercises, participation in physical education classes, and sport training.

Participants were evaluated in the morning or early afternoon, not after physical exercise class. They were instructed not to eat for at least 2 hours prior to measurements.

\section{Methods}

Body height $(\mathrm{BH})$ was measured with a medical scale using a height meter (with an accuracy of $5 \mathrm{~mm}$ ). Body mass (BM), fat mass (FM), percent of fat (fat \%) and total body water (TBW) were measured using the Tanita-410 (with an accuracy of $0.1 \mathrm{~kg}$ and $0.5 \%$ ). The Tanita Body Composition Analyzer (Tokyo, Japan) is a device that determines BM, FM and fat-free mass (FFM) based on bioelectrical impedance analysis. Body mass index (BMI) was estimated on the basis of $\mathrm{BH}$ and $\mathrm{BM}$.

To assess posture, specialized computer equipment based on the moiré method was used. The moiré method provides a 3-dimensional picture of the back and it analyses over 50 parameters describing posture with accuracy of $1 \mathrm{~mm}$ and $1^{\circ}[2,5,8]$.

The tested student stood with his/her back to the camera recording the image in an habitual posture. All participants were measured barefoot wearing only underwear.

The spinal posture analysis included:

- the angular disposition of the upper segment of the thoracic curve - angle $\alpha\left[^{\circ}\right]$,

- the angular disposition of the thoracolumbar segment curve - angle $\beta\left[^{\circ}\right]$,

- the angular disposition of the lumbosacral segment curve - angle $\gamma\left[{ }^{\circ}\right]$,

- the sum of all the spine's angles in the sagittal plane $(\alpha+\beta+\gamma)-$ angle $\Delta\left[^{\circ}\right]$,

- the kyphosis thoracic angle $(\alpha+\beta)(\mathrm{KThA})\left[^{\circ}\right]$,

- the lordosis lumbar angle (LLA) $(\beta+\gamma)\left[^{\circ}\right]$ (Fig. 1).

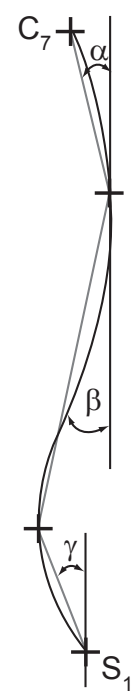

Fig. 1. Diagram of spinal posture in the sagittal plane

\section{Statistical analysis}

Results of somatic and posture characteristic in girls and boys were compared with the t-test or Mann-Whitney U-test. The normality of distribution was verified with the Kolmogorov-Smirnov test. Homogeneity of variance was verified with the Levene test. To determine the potential impact of the studied traits of somatic development and the age on the spinal posture, Pearson's r correlation coefficient (linear correlation coefficient) or the Spearman correlation coefficient was applied.

Multiple analysis of variance and the Tukey test for unequal sample sizes were used to assess whether posture parameters varied in the entire group with respect to age 
and gender. For conducting the MANOVA and Tukey tests the participants were divided into three groups of age: the first group of participants were between 8 and 10 years old, the second group of participants were between 11 and 13 years old, and the third group of participants were between 14 and 16 years old.

The level of significance was set at $\alpha=0.05$. The statistical analysis was performed using STATISTICA v. 10 software (Stat soft Inc., USA).

\section{Results}

The tables present the results of measurements of somatic and posture characteristics. Statistically significant differences in the examined parameters between boys and girls in the relevant age groups are indicated with the probability level (p) (Table 1).
Analysis of spinal posture revealed cross-gender differences mainly in the shape of lumbar lordosis, which was significantly larger in the 9-year-old, 15- and 16-yearold girls (Table 2).

The analysis of the correlations between spinal posture indicators and anthropometric characteristics and age revealed the following relationships in the group of girls:

Angle $\alpha$ was correlated with fat mass $(0.14)$, fat $\%$ (0.15), and BMI (0.13);

Angle $\Delta$ was correlated with fat mass $(0.11)$, fat $\%$ (0.14), and BMI (0.13).

Angle $\beta$, angle $\gamma$, kyphosis and lordosis angles were not correlated with anthropometric parameters. Age was not correlated with any spinal posture indicators.

In the group of boys the following correlations were noted:

Angle $\beta$ was correlated with body mass $(-0.14)$, fat mass $(-0.13)$, TBW $(-0.12)$, and BMI $(-0.16)$;

Table 1. Mean values ( $\pm \mathrm{SD}$ ) of anthropometric parameters in girls (F) and boys (M)

\begin{tabular}{|c|c|c|c|c|c|c|c|}
\hline Age & Gender, $\mathrm{n}$ & $\mathrm{BH}[\mathrm{cm}]$ & $\mathrm{BM}[\mathrm{kg}]$ & FM [kg] & $\mathrm{FM}[\%]$ & TBW [kg] & $\mathrm{BMI}\left[\mathrm{kg} / \mathrm{m}^{2}\right]$ \\
\hline \multirow[t]{2}{*}{8} & $\mathrm{~F}(\mathrm{n}=30)$ & $123.77 \pm 6.28^{*}$ & $23.77 \pm 5.22 *$ & $3.09 \pm 2.56^{*}$ & $11.67 \pm 7.04 *$ & $15.18 \pm 2.11^{*}$ & $15.37 \pm 2.08$ \\
\hline & $M(n=29)$ & $\begin{array}{c}127.86 \pm 6.24^{*} \\
\mathrm{p}=0.015\end{array}$ & $\begin{array}{c}27.43 \pm 6.63^{*} \\
p=0.022\end{array}$ & $\begin{array}{c}4.78 \pm 3.34^{*} \\
p=0.016\end{array}$ & $\begin{array}{c}16.07 \pm 7.04^{*} \\
\mathrm{p}=0.02\end{array}$ & $\begin{array}{c}16.59 \pm 2.61^{*} \\
\mathrm{p}=0.026\end{array}$ & $16.68 \pm 3.04$ \\
\hline \multirow[t]{2}{*}{9} & $F(n=26)$ & $133.12 \pm 5.51$ & $30.18 \pm 5.97$ & $5.43 \pm 3.45$ & $16.8 \pm 7.19$ & $18.11 \pm 2.14$ & $16.92 \pm 2.34$ \\
\hline & $M(n=25)$ & $132.28 \pm 5.27$ & $30.63 \pm 6.17$ & $5.22 \pm 3.09$ & $16.04 \pm 6.48$ & $18.6 \pm 2.72$ & $17.4 \pm 2.79$ \\
\hline \multirow[t]{2}{*}{10} & $\mathrm{~F}(\mathrm{n}=33)$ & $136.92 \pm 7.96^{*}$ & $33.99 \pm 7.81 *$ & $6.32 \pm 4.6$ & $16.99 \pm 8.39$ & $20.19 \pm 2.94 *$ & $17.98 \pm 2.95$ \\
\hline & $M(n=29)$ & $\begin{array}{c}141.97 \pm 5.94^{*} \\
\mathrm{p}=0.008\end{array}$ & $\begin{array}{c}38.42 \pm 8.4^{*} \\
\mathrm{p}=0.035\end{array}$ & $7.36 \pm 4.54$ & $17.88 \pm 7.26$ & $\begin{array}{c}22.75 \pm 3.29 * \\
\mathrm{p}=0.005\end{array}$ & $18.99 \pm 3.61$ \\
\hline \multirow[t]{2}{*}{11} & $\mathrm{~F}(\mathrm{n}=49)$ & $145.2 \pm 6.78$ & $38.1 \pm 6.69$ & $7.62 \pm 3.89$ & $19.21 \pm 7.58$ & $22.32 \pm 2.85$ & $17.99 \pm 2.48$ \\
\hline & $M(n=37)$ & $144.81 \pm 6.9$ & $40.27 \pm 12.76$ & $7.5 \pm 6.38$ & $16.44 \pm 8.03$ & $23.99 \pm 4.91$ & $18.93 \pm 4.34$ \\
\hline \multirow[t]{2}{*}{12} & $\mathrm{~F}(\mathrm{n}=38)$ & $152.11 \pm 8.06$ & $41.25 \pm 6.97$ & $6.63 \pm 3.89$ & $15.49 \pm 6.5$ & $25.42 \pm 2.71$ & $17.74 \pm 1.9 *$ \\
\hline & $M(n=37)$ & $148.88 \pm 7.59$ & $43.52 \pm 9.06$ & $6.74 \pm 4.03$ & $14.6 \pm 6.27$ & $26.93 \pm 4.37$ & $\begin{array}{c}19.48 \pm 2.81 * \\
\mathrm{p}=0.002\end{array}$ \\
\hline \multirow[t]{2}{*}{13} & $\mathrm{~F}(\mathrm{n}=48)$ & $158.42 \pm 6.96^{*}$ & $48.31 \pm 7.99$ & $9.65 \pm 5.06^{*}$ & $19.09 \pm 7.82 *$ & $28.34 \pm 3.27$ & $19.17 \pm 2.30$ \\
\hline & $M(n=43)$ & $\begin{array}{c}155.27 \pm 5.81 * \\
\mathrm{p}=0.022\end{array}$ & $46.84 \pm 9.07$ & $\begin{array}{c}6.76 \pm 4.45^{*} \\
p=0.001\end{array}$ & $\begin{array}{c}13.59 \pm 6.62 * \\
\mathrm{p}<0.001\end{array}$ & $29.35 \pm 4.45$ & $19.33 \pm 2.94$ \\
\hline \multirow[t]{2}{*}{14} & $\mathrm{~F}(\mathrm{n}=28)$ & $159.21 \pm 4.71 *$ & $49.53 \pm 7.17 *$ & $10.52 \pm 5.50$ & $20.24 \pm 8.56^{*}$ & $28.56 \pm 2.36^{*}$ & $19.50 \pm 2.39$ \\
\hline & $M(n=24)$ & $\begin{array}{c}166.83 \pm 8.34^{*} \\
\mathrm{p}<0.001\end{array}$ & $\begin{array}{c}58.05 \pm 10.42 * \\
\mathrm{p}=0.002\end{array}$ & $7.94 \pm 5.98$ & $\begin{array}{c}12.92 \pm 7.41^{*} \\
\mathrm{p}<0.001\end{array}$ & $\begin{array}{c}36.66 \pm 5.25^{*} \\
\mathrm{p}<0.001\end{array}$ & $20.80 \pm 3.05$ \\
\hline \multirow[t]{2}{*}{15} & $\mathrm{~F}(\mathrm{n}=39)$ & $163.49 \pm 5.85^{*}$ & $55.72 \pm 10.15$ & $14.54 \pm 7.40 *$ & $29.02 \pm 22.84 *$ & $30.48 \pm 3.31 *$ & $20.78 \pm 3.18$ \\
\hline & $M(n=38)$ & $\begin{array}{c}170.46 \pm 7.64^{*} \\
\mathrm{p}<0.001\end{array}$ & $59.15 \pm 10.53$ & $\begin{array}{c}6.42 \pm 3.97^{*} \\
p<0.001\end{array}$ & $\begin{array}{c}10.36 \pm 4.84^{*} \\
\mathrm{p}<0.001\end{array}$ & $\begin{array}{c}38.43 \pm 5.64^{*} \\
\mathrm{p}<0.001\end{array}$ & $20.28 \pm 2.63$ \\
\hline \multirow[t]{2}{*}{16} & $F(n=40)$ & $163.94 \pm 5.72 *$ & $56 \pm 9.92 *$ & $14.14 \pm 6.41^{*}$ & $24.31 \pm 7.35^{*}$ & $30.81 \pm 3.32 *$ & $20.81 \pm 3.4$ \\
\hline & $M(n=25)$ & $\begin{array}{c}177.1 \pm 5.84^{*} \\
\mathrm{p}<0.001\end{array}$ & $\begin{array}{c}63.74 \pm 6.94^{*} \\
p<0.001\end{array}$ & $\begin{array}{c}7.35 \pm 5.1 * \\
p<0.001\end{array}$ & $\begin{array}{c}11.08 \pm 6.85^{*} \\
\mathrm{p}<0.001\end{array}$ & $\begin{array}{c}41.28 \pm 3.62 * \\
\mathrm{p}<0.001\end{array}$ & $20.34 \pm 2.25$ \\
\hline
\end{tabular}


Table 2. Mean values $( \pm \mathrm{SD})$ of sagittal spinal curvatures in girls $(\mathrm{F})$ and boys $(\mathrm{M})$

\begin{tabular}{|c|c|c|c|c|c|c|c|}
\hline Age & Gender & $\alpha$ angle $\left[^{\circ}\right]$ & $\beta$ angle $\left[{ }^{\circ}\right]$ & $\gamma$ angle $\left[^{\circ}\right]$ & $\Delta$ angle $\left[^{\circ}\right]$ & $\begin{array}{l}\text { Kyphosis angle } \\
(\alpha+\beta)\end{array}$ & $\begin{array}{c}\text { Lordosis angle } \\
\qquad(\beta+\gamma)\end{array}$ \\
\hline \multirow[t]{2}{*}{8} & $\mathrm{~F}$ & $14.16 \pm 3.78^{*}$ & $14.94 \pm 3.54$ & $13.59 \pm 5.9$ & $42.69 \pm 8.35$ & $29.1 \pm 5.07$ & $28.53 \pm 7.03$ \\
\hline & M & $\begin{array}{c}16.35 \pm 3.23^{*} \\
\mathrm{p}=0.02\end{array}$ & $14.27 \pm 3.35$ & $13.31 \pm 6.88$ & $43.93 \pm 7.79$ & $30.62 \pm 4.69$ & $27.58 \pm 8.01$ \\
\hline \multirow[t]{2}{*}{9} & $\mathrm{~F}$ & $13.07 \pm 4.29$ & $13.06 \pm 4.24$ & $16.98 \pm 6.53 *$ & $43.11 \pm 9.05$ & $26.13 \pm 6.95$ & $30.04 \pm 8.42$ \\
\hline & M & $14.79 \pm 4.65$ & $14.50 \pm 3.31$ & $\begin{array}{c}12.97 \pm 5.59 * \\
\mathrm{p}=0.046\end{array}$ & $42.25 \pm 7.20$ & $29.28 \pm 5.44$ & $27.47 \pm 6.28$ \\
\hline \multirow[t]{2}{*}{10} & $\mathrm{~F}$ & $16.84 \pm 4.34$ & $14.64 \pm 3.47$ & $15.91 \pm 5.46$ & $47.39 \pm 7.79$ & $31.48 \pm 6.48$ & $30.55 \pm 6.21$ \\
\hline & M & $16.24 \pm 4.88$ & $13.22 \pm 3.63$ & $17.84 \pm 5.59$ & $47.3 \pm 7.32$ & $29.46 \pm 5.85$ & $31.06 \pm 6.53$ \\
\hline \multirow[t]{2}{*}{11} & $\mathrm{~F}$ & $14.79 \pm 4.99$ & $13.14 \pm 3.57$ & $16.67 \pm 4.76$ & $44.6 \pm 7.29$ & $27.93 \pm 6.81 *$ & $29.8 \pm 5.5$ \\
\hline & M & $16.66 \pm 4.33$ & $14.48 \pm 2.64$ & $14.88 \pm 5.45$ & $46.02 \pm 7.24$ & $\begin{array}{c}31.13 \pm 5.67^{*} \\
p=0.023\end{array}$ & $29.36 \pm 5.77$ \\
\hline \multirow[t]{2}{*}{12} & $\mathrm{~F}$ & $15.76 \pm 4.1$ & $13.99 \pm 2.75$ & $14.62 \pm 4.97$ & $44.38 \pm 7.07$ & $29.76 \pm 5.39$ & $28.62 \pm 6.03$ \\
\hline & M & $14.56 \pm 4.68$ & $13.07 \pm 3.13$ & $14.63 \pm 5.84$ & $42.26 \pm 8.74$ & $27.63 \pm 5.72$ & $27.7 \pm 6.92$ \\
\hline \multirow[t]{2}{*}{13} & $\mathrm{~F}$ & $14.95 \pm 3.82$ & $14.48 \pm 2.71$ & $14.08 \pm 6.16$ & $43.51 \pm 7.62$ & $29.43 \pm 5.05$ & $28.56 \pm 6.74$ \\
\hline & M & $15.44 \pm 3.26$ & $14.12 \pm 2.75$ & $13.82 \pm 5.76$ & $43.38 \pm 7.19$ & $29.56 \pm 4.41$ & $27.94 \pm 6.63$ \\
\hline \multirow[t]{2}{*}{14} & $\mathrm{~F}$ & $13.82 \pm 5.26$ & $14.28 \pm 3.16$ & $15.76 \pm 5.44$ & $43.86 \pm 9.8$ & $28.1 \pm 7.18$ & $30.04 \pm 7.02$ \\
\hline & M & $15.06 \pm 3.76$ & $14.2 \pm 2.53$ & $13.47 \pm 4.68$ & $42.72 \pm 6.85$ & $29.26 \pm 4.75$ & $27.66 \pm 6.04$ \\
\hline \multirow[t]{2}{*}{15} & $\mathrm{~F}$ & $14.71 \pm 3.56$ & $14.91 \pm 2.68$ & $15.95 \pm 7.24 *$ & $45.57 \pm 8.57 *$ & $29.62 \pm 4.56$ & $30.86 \pm 8.12 *$ \\
\hline & M & $15.41 \pm 3.66$ & $13.69 \pm 2.98$ & $\begin{array}{c}12.03 \pm 6.18^{*} \\
p=0.014\end{array}$ & $\begin{array}{c}41.13 \pm 7.52^{*} \\
\mathrm{p}=0.018\end{array}$ & $29.1 \pm 5.33$ & $\begin{array}{c}25.72 \pm 6.34^{*} \\
p=0.009\end{array}$ \\
\hline \multirow[t]{2}{*}{16} & $\mathrm{~F}$ & $14.53 \pm 4.22$ & $15.07 \pm 2.08$ & $14.34 \pm 5.31 *$ & $43.93 \pm 7.69$ & $29.59 \pm 5.18$ & $29.4 \pm 6.02 *$ \\
\hline & M & $16.04 \pm 3.71$ & $13.94 \pm 2.66$ & $\begin{array}{c}10.26 \pm 4.07 * \\
\mathrm{p}=0.002\end{array}$ & $40.24 \pm 6.23$ & $29.98 \pm 5.65$ & $\begin{array}{c}24.2 \pm 4.39 * \\
\mathrm{p}<0.001\end{array}$ \\
\hline
\end{tabular}

Angle $\gamma$ was correlated with body height $(-0.17)$, fat $\%$ (0.15), TBW (-0.13), and age $(-0.2)$;

Angle $\Delta$ was correlated with body height $(-0.17)$, fat $\%$ (0.13), TBW (-0.15), and age $(-0.19)$;

LLA was correlated with body height $(-0.19)$, body mass $(-0.13)$, TBW $(-0.17)$, and age $(-0.21)$.

Angle $\alpha$ and KThA were not correlated with anthropometric parameters.

Multiple analysis of variance (MANOVA) indicated significant differences in angle $\alpha$ (gender: $p=0.015$ ), angle $\gamma$ (age: $p=0.029$, gender: $p<0.001$, age*gender: $\mathrm{p}=0.032$ ), and lordosis angle (gender: $\mathrm{p}<0.001$, age*gender: $\mathrm{p}=0.011$ ).

The post-hoc test (Tukey test) revealed significant differences in angle $\gamma$ and also in lumbar lordosis angle between: boys aged 14-16 years and girls aged 8-10 years (angle $\gamma: \mathrm{p}<0.001$ lumbar lordosis angle: $\mathrm{p}=0.001$ ); boys aged 14-16 years and boys aged 8-10 (respectively: $\mathrm{p}=0.018$, and $\mathrm{p}=0.048)$; boys aged $14-16$ years and girls aged $11-13$ years $(p=0.003$, and $p=0.017)$; and boys and girls aged $14-16$ years $(p=0.002$, and $p<0.001)$. The post hoc test did not reveal any significant differences in angle $\alpha$.

It should be noted that age was significantly correlated with the somatic parameters of: $\mathrm{BH} 0.87$ in girls and 0.91 in boys, respectively, BM 0.8, and 0.77, FM 0.57 (correlation statistically significant only in girls), fat \% 0.34 and -0.3 , TBW 0.86 and 0.87, and BMI 0.51 and 0.34 .

\section{Discussion}

The aim of this study was to assess the sagittal spinal curvatures of girls and boys ages 8-16, and to identify individual variations that can determine spinal posture.

Dimorphic postural differences of boys and girls were seen mainly in the shape of lumbar lordosis. Girls were more lordotic at all ages except 10-years-olds. Angle $\gamma$ was greater in girls than boys of all age groups, but a statistically significant difference was noted only in 9-, 15and 16-year-olds. LLA was statistically significant only in groups of 15- and 16-year-olds. Thoracic kyphosis was 
more prominent in most boys, but the differences were statistically significant only in 8-and 11-year-olds. Our results are confirmed by studies by Widhe [20], DrzałGrabiec et al. [3], and Poussa et al. [16], but they do not agree with the results of Mac-Thiong et al., in which there was no significant difference between boys and girls aged 4-18 [12]. The results of Szczepanowska-Wołowiec et al., who used the same measurement technique, also confirmed the variation of different posture types based on gender, and revealed an increase of thoracic kyphosis in boys [19]. In the study of Penha et al. there were cross-generational differences in the position of the head, shoulders, and in the form of cervical lordosis. The authors concluded that the specific gender abnormalities were related to muscle, skeletal and flexibility differences [14].

Our study revealed correlations in spinal curvatures of boys with regard to their age but did not find correlations with the spinal curvatures of the girls. MANOVA and post hoc tests confirmed differences only in angle $\gamma$ and the lumbar lordosis angle with respect to age and gender. Mean lumbar lordosis was more pronounced in 10-yearold boys, likely due to the greater strength of the back muscles, and less pronounced in the oldest groups of boys. Based on those analyses we may confirm differences in the shape of lumbar lordosis in children and adolescents. The findings suggested that lumbar lordosis decreases together with age in male children and adolescents. Researchers evaluating posture in the sagittal plane of children from the province of Świetokrzyskie, using the same method, did not observe similar regularities, but noted predominantly kyphotic type in boys aged 10-12 [19]. However, the authors did not specify the angles of thoracic kyphosis and lumbar lordosis, so direct comparison of the angles is impossible. Lafond et al. in their study of posture in the sagittal plane in a large population of children and adolescents aged 4-12 observed a significant main effect of age and gender [9]. Cil et al. revealed a significant difference among different age groups for thoracic kyphosis and lumbar lordosis angles. Thoracic kyphosis and lumbar lordosis increased with growth, while the thoracic apex moved upwards with growth [1]. Our study did not confirm that conclusion. Drzał-Grabiec et al. also reported that spinal curvatures changed with age [3].

Our results showed correlations of spinal posture with somatic parameters. These correlations can be interpreted as follows: the girls with a higher percentage of body fat and FM were more likely to have increased AP curvatures of the spine (especially the angle of the upper thoracic segment). Boys with higher FM, fat \%, and higher BMI were more prone to side curvatures of the spine. Greater BM, FM, TBW and BMI were associated with a smaller angle $\beta$. It should be noted that the low magnitude of several correlations makes us cautious regarding the strength of the relationships between the variables under investigation. The literature also discusses the relationship between posture and somatic parameters. Lichota in her study of posture of 13-year-olds found that the anteroposterior (AP) curvatures of the spine were more pronounced in tall-statured girls and boys than in short-statured peers [11]. In our study we observed a similar phenomenon among boys. Studies comparing the posture of the groups formed on the basis of BMI showed an exaggeration of AP curvatures in children and adolescents, especially girls with a higher BMI compared to the group with a normal BMI or below the norm [4]. Smith et al. reported that hyperlordotic and sway standing postures were associated with a higher BMI. They also suggested that obese and overweight children are more vulnerable to back pain associated with increased lumbar lordosis [18]. Poussa et al. based on their longitudinal study of 11- to 22-year-old individuals did not find a relationship between BMI and thoracic kyphosis [16].

\section{Conclusions}

The shape of lumbar lordosis is associated with age and gender. Lumbar lordosis decreases with age in male children and adolescents. The most prominent AP curvatures were noted in 10-year-old male and female children. Girls were more lordotic than boys at all ages except 10years-olds. Our study revealed a relationship between sagittal curvatures and somatic parameters, but the observed correlations were weak.

\section{Conflict of interest: Authors state no conflict of interest.}

\section{References}

1. Cil A., M. Yazici, A. Uzumcuqil, U. Kandemir, A. Alanay, Y. Alanay, R.E. Acaroglu, A. Surat (2005) The evolution of sagittal segmental alignment of the spine during childhood. Spine, 30: 93-100.

2. Drzał-Grabiec J., S. Snela (2012) The influence of rural environment on body posture. Ann. Agric. Envinron. Med., 19: 846-850.

3. Drzał-Grabiec J., S. Snela, A. Truszczyńska (2016) The development of anterior-posterior spinal curvature in children aged 7-12 years. Biomed. Hum. Kinet., 8: 72-82.

4. Grabara M., D. Pstragowska (2008) Estimation of the body posture in girls and boys related to their body mass index (BMI). Pol. J. Sport Med., 4: 231-239.

5. Grabara M. (2014) A comparison of the posture between young female handball players and non-training peers. J. Back Musculoskelet. Rehabil., 27: 85-92. DOI: 10.3233/BMR-130423. 
6. Grabara M. (2016) Sagittal spinal curvatures in adolescent male basketball players and non-training individuals - a two-year study. Sci. Sports, 31: 147-153. DOI: 10.1016/j.scispo.2016.01.010.

7. Hagner W., D. Bąk, M. Hagner-Derengowska (2010) Posture difference among school children in first three year of elementary school. Via Medica, 287-290. ISSN 1897-3590.

8. Janiszewska R., S. Tuzinek, S. Nowak, A. Ratyńska, T. Biniaszewski (2009) Abnormalities of posture in 6-12 year-old children - pupils of primary schools from Radom - a pilot study. Probl. Hig. Epidemiol., 90: 342-346.

9. Lafond D., M. Descarreaux, M.C. Normand, D.E. Harrison (2007) Postural development in school children: a cross-sectional study. Chiropr. Osteopat., 15: 1. DOI: 10.1186/1746-1340-15-1.

10. Lang-Tapia M., V. España-Romero, J. Anelo, M.J. Castillo (2011) Differences on spinal curvature in standing position by gender, age and weight status using a noninvasive method. J. Appl. Biomech., 27: 143-150.

11. Lichota M. (2008) Spine shape in sagittal and frontal planes in short- and tall-statured children aged 13 years. Phys. Edu. Sport, 52: 92-95.

12. Mac-Thiong J.M., É. Berthonnaud, J. Dimar, R. Betz, H. Labelle (2004) Sagittal alignment of the spine and pelvis during growth. Spine, 29: 1642-1647.

13. Murata Y., T. Utsumi, E. Hanaoka, K. Takahashi, M. Yamagata, H. Moriya (2002) Changes in lumbar lordosis in young patients with low back pain during a 10-year period. J. Ortop. Sci., 7: 618-622.

14. Penha P.J., R.A. Casarotto, I.C.N. Sacco, A.P. Marques, S.M.A João (2008) Qualitative postural analysis among boys and girls of seven to ten years of age. Rev. Bras. Fisioter., 12: 386-391.
15. Perry M., A. Smith, L. Straker, J. Coleman, P. O’Sullivan (2008) Reliability of sagittal photographic spinal posture assessment in adolescents. Advanc. Physiother., 10: 66-75. DOI: 10.1080/14038190701728251.

16. Poussa M.S., M.M. Heliövaara, J.T. Seitsamo, M.H. Könönen, K.A. Hurmerinta, M.J. Nissinen (2005) Development of spinal posture in a cohort of children from the age of 11 to 22 years. Eu. Spine J., 14: 738-742.

17. Proszkowiec M., K. Słonka, L. Hyla-Klekot (2011) Formation of body posture in the 2 nd critical stage of postural development with regard to sexual maturity of subjects. Fizjoter., 19: 10-19.

18. Smith, A.J., P.B. O’Sullivan, D.J. Beales, N. Klerk, L.M. Straker (2011) Trajectories of childhood body mass index are associated with adolescent sagittal standing posture. Int. J. Pediatr. Obes., 6: e97-e106.

19. Szczepanowska-Wołowiec B., J. Drzał Grabiec, P. Sztandera, J. Dudek, I. Kotela (2012) Bad posture in the sagittal plane of children aged 10-12 from the świętokrzyskie voivodeship. Medical Studies, 27: 31-35.

20. Widhe T (2001) Spine, posture, mobility and pain. A longitudinal study from childhood to adolescence. Eu. Spine J., 10: 118-123.

21. Zeyland-Malawka E. (1989) Effects prolonged sport training on the sagittal shape of the spine. Biol. Sport, 6: 255-260.

\section{Received 14.02.2017 \\ Accepted 05.05.2017}

(C) University of Physical Education, Warsaw, Poland 